\title{
Defining Leadership: Collegiate Women's Learning Circles: A Qualitative Approach
}

\author{
Tammie Preston-Cunningham \\ Assistant Lecturer \\ Texas A\&M University \\ Chanda D. Elbert \\ Associate Professor \\ Texas A\&M University \\ Kim E. Dooley \\ Associate Dean for Academic Operations \\ Texas A\&M University
}

\begin{abstract}
The researchers employed qualitative methods to evaluate first-year female students' definition of leadership through involvement in the Women's Learning Circle. The findings revealed that students defined leadership in two dimensions: traits and behaviors. The qualitative findings explore a multidimensional approach to the voices of 54 female students.
\end{abstract}

\section{Introduction}

According to Chickering and Reisser (1993), the transition to college is a time for students to explore themselves and develop an identity. According to Tinto (1993), individuals may struggle to integrate into either the academic or the social realm while integrating smoothly into the other realm. The ability to integrate socially enhances the student's college success. In the field of student affairs, the co-curricular plays an intricate and important role in the overall success of the college student. Students' social integration is often met through involvement in student organizations. Student organizations offer students opportunities to construct social networks and practice leadership skills. Participation in student organizations is seen as an integral component of students gaining leadership experience; however "participants may experience leadership differently based on the organization and its cultural context" (Logue, Hutchens, \& Hector, 2005, p. 406). There is a need for research focused on specific involvement areas (Gellin, 2003).

According to Thorp, Cummins, and Townsend (1998), greater exposure to leadership courses and prior leadership activities in high school leads to increased confidence in females' perceived leadership skills in college. Therefore, this research explores the definition of leadership presented by freshmen sorority women upon entry to college. This issue is important as the number of women attending college continues to grow, making it necessary to develop effective leadership training programs that increase leadership role attainment among women. 
The purpose of this study was to investigate how sorority undergraduate students defined and characterized their leadership before participation in an extended leadership program. The research question that guided the study was, how do freshmen undergraduate students define leadership?

The review of the literature enabled the researchers to grasp how leadership evolves through involvement in student organizations and how participation in leadership training programs may influence success by female undergraduate students in higher education.

\section{Literature Review}

In the field of student affairs, the co-curricular plays an intricate and important role in the overall success of the college student. This study utilized the social integration framework as a guide to understanding the perceptions and expectations of leadership within a sorority-centered student program. The following terms are integral to understanding the subject matter: social integration, leadership, and leadership training programs.

Social Integration. Tinto (1993) characterized each academic system as having formal and informal aspects. Academic performance is the formal aspect of the academic system, while campus-inspired extracurricular activities are the informal component of the social system. Similarly, interactions with faculty and staff comprise the informal aspect of the academic system, while interactions with peers constitutes the informal social system. Successful negotiation of those two systems leads to academic and social integration, respectively. According to the Tinto (1993) model, there are three distinct stages of transition: (a) separation from communities of the past, (b) release of past norms and behaviors and adoption of new norms appropriate for the new environment, and (c) incorporation into the social system of the new environment. Tinto (1993) noted that the final stage has an influence on determination of persistence and that failure to integrate into the campus environment results in withdrawal from college.

This research was aligned with that of other researchers who stated that pre-existing contributing factors such as family background, aptitude, and prior academic and social preparation play a significant role in successful adjustment by freshmen. According to Smedley, Myers, and Harrell (1993), four factors contribute to adjustment: (a) academic preparedness, (b) psychological stress, (c) sociocultural stresses, and (d) integration. For the purpose of this study, integration was the focus as a primary factor.

Tinto (1993) postulated that social integration can be met by myriad methods but is met primarily through involvement with student organizations. As students become involved in an organization, it is a natural progression for those students to become leaders. Leadership development is now an integral part of the educational program of college students, with courses and activities scattered throughout the co-curricular experience. Komives, Lucas, and McMahon (1998) argued that leadership, like any other skill, must be learned and practiced. 
Leadership. Pascarella and Terenzini's (2005) analysis of research conducted in the previous 30 years indicated a growing body of knowledge that consistently demonstrates that students increase their leadership skills while in college. Astin (1993) asserted that student involvement has the potential to enhance most aspects of the undergraduate student's cognitive and affective development. One popular aspect of co-curricular life on campus is student organizations, which incorporate two of the "three most potent forms of involvement" (Astin, 1996, p. 126): faculty and student groups. Researchers have defined leadership as a process whereby one individual influences a group of individuals to achieve a common goal.

Taking into account the context of leadership within an organization, Nahavandi (2006) described a leader as a person who influences individuals and groups within an organization, helps them to establish goals, and guides them toward achievement of those goals, thereby allowing them to be effective. While identifying leadership based on traits, Nahavandi (2006) expressed that behavioral theorists focus on behaviors and thus it is important that a leader's behavior be based on traits and skills.

In this regard, Lussier and Achua (2007) identified nine traits of effective leaders: (a) dominance, (b) high energy, (c) self-confidence, (d) locus of control, (e) stability, (f) integrity, (g) intelligence, (h) emotional intelligence, and (i) flexibility and sensitivity to others. Similar research by Burns (1978) identified a set of behavioral traits based on a historical perspective: intelligence, self-confidence, determination, integrity, and sociability. Thus, the review of the literature related to practices of leadership and behavior led the authors to a similar framework of transformational leadership.

As researchers continue to delve into the process of leadership, Kouzes and Posner (2008) identified five practices of exemplary leadership: (a) model the way, (b) inspire a shared vision, (c) challenge the process, (d) enable others to act, and (e) encourage the heart. These practices have been characterized as personal leadership experiences. For instance, while modeling the way, one should behave in a way in which one would expect others to behave. In order to inspire a shared vision, one must see farther than the present and have knowledge about others' dreams, hopes, aspirations, visions, and values. In challenging the process, when obstacles arise, a leader continues to strive to succeed. When enabling others to act, one must first build trust as a team and encourage others to become leaders. To encourage the heart is to show an appreciation for others' contributions and celebrate their accomplishments. As the practices of leadership were discussed, behavior was clearly an essential feature that intertwines within all five practices.

Burns (1978) stated that transformational leadership is a process that changes and transforms people. Likewise, Elias, O'Brien, and Weissberg (2006) described transformative leadership as "leadership that is willing to realign structures and relationships to achieve genuine and sustainable change" (p. 10). According to Lussier and Achua (2007), effective transformational leaders see themselves as change agents, visionaries, and risk takers with the ability to articulate core values; they possess cognitive skills, are able to show sensitivity and flexibility, and are open to learn from experience. Bass (1990) expressed it best: 
Transformation leaders ask their followers to transcend their self-interest for the good of the organization; to consider the long-term needs to develop themselves, rather than their needs of the moment; and to become more aware of what is really important. (p. 53)

Gender and Leadership Issues. Bass (1990) stated that women in the past had limited leadership opportunities; typically, women were relegated to "women's issues" and jobs in institutions such as sororities, nunneries, and all-girl schools. Currently, leadership opportunities for women have increased; however, the glass ceiling continues to exist between upper-middle management and the executive level (Lussier \& Achua, 2007). In relation to gender and traits, Hoyt (2007) concluded that it is unclear how important traits are to leadership. However, Hoyt expressed that gender is integral to contemporary notions of effective leadership styles that have morphed from a traditional masculine, autocratic style to the more feminine and androgynous styles of democratic and transformational leadership. Adams and Keim (2000) found that sorority chapter presidents took a more participative/collaborative approach and practice of developing a trusting and supporting environment and encouraging others to develop leadership skills than did men.

Research by Kezar and Moriarty (2000) showed membership in a sorority to be a significant predictor of leadership ability among White women. They found that involvement in various activities, such as community service, membership in a campus organization, holding an officer position, and participation in a formal leadership program had differential impacts on students' leadership development and that this influence was differentiated by gender and ethnicity. Although gender was not found to explain differences in the impact of participation in leadership development programs (Endress, 2000; Pugh, 2000) or to account for differences in leadership behaviors (Posner, 2004; Posner \& Brodsky, 1994), others have reported that males and females respond to different leadership paradigms (Eagly \& Carli, 2003; Eagly, JohannesenSchmidt, \& van Engen, 2003; Romano, 1996). Dugan (2006), for example, reported that college women scored higher than their male counterparts across all eight of the constructs associated with a social change model of leadership.

Leadership Training Programs. Cress, Astin, Zimmerman-Oster, and Burkhart (2001) found that leadership development programs influenced educational and personal development. They concluded that "leadership potential exists in every student, and colleges and universities can develop this potential through programs and activities" (p. 23). Further support for this conclusion comes both from Lamborghini and Dittemer's (2002) study at Northern Essex Community College, where 95\% of the respondents reported that their leadership development program had improved leadership skills, and from Polleys's (2002) study of students who completed the Columbus State University Servant-Leadership Program. Garza (2000) found that, 10 years after completing college student leadership programs, participants perceived that the program had affected their acquisition of leadership skills and job competencies necessary for advanced leadership positions and had influenced their pursuit of graduate studies.

Pascarella and Terenzini's (2005) analysis of research during the previous 30 years indicated a growing body of knowledge that consistently demonstrates that students increase their leadership skills while in college. Astin (1993) asserted that student involvement has the 
potential to enhance most aspects of the undergraduate student's cognitive and affective development. Research has highlighted various leadership roles within specific types of student organizations, including student leaders from one or more of the following: fraternities and sororities, minority groups, religion-affiliated groups, class presidents, student government, newspaper editors, residence hall councils, disciplinary boards, union boards, boards of trustees, and academic organizations (Kuh \& Lund, 1994; Logue et al., 2005; Posner \& Brodsky, 1994; Romano, 1996).

\section{Methods and Procedures}

The current study utilized a qualitative methodology to evaluate the emerging themes and capture the nuances within the population (Hughes \& DuMont, 1993). Given that "it is not possible to understand any phenomenon without reference to the context in which it is embedded" (Lincoln \& Guba, 1985, p. 302), in order to understand the student leadership experience in postsecondary settings, the context must be thoroughly appreciated and understood. One of the underlying philosophies that guided this study was the constructivist paradigm, which was well suited to the design of the study due to its ability to offer students voice. Thompson (2000) states that constructivism may be used to build a theory of learning. It is used to make meaning from knowledge in which the learner has already known. The encouragement of the learner to construct and make meaning of the interaction through their personal experiences and be socially supported is pivotal to creating knowledge and should be included in designing research studies focused on college-aged students. The learning process through the lens of constructivism creates a cornucopia of active meaning making and socially supported interactions.

In qualitative research, the opportunities for generating new ideas and frameworks, as well as lending a voice to the research participant, ensure a complex and multifaceted exploration of the topic. This approach was well suited to the design of this study for several reasons. The emphasis on a relativist ontology recognizes multiple realities (Guba, 1990) and the subjectivist epistemological approach "involves interaction between the researcher and the participant so that the findings are literally created during the process of the study" (Appleton \& King, 1997, p. 111).

The bounded system for this study was a campus leadership program designed for firstsemester freshmen women at a large predominately White institution in Texas. The researchers were interested in studying students who had not yet held a collegiate leadership position in order to explore how they created their own meaning of leadership. The researchers explored whether the program participants' description of their skill set might be different from that of their sorority counterparts who had actually held leadership roles at other institutions.

Thus, the researchers focused on questions related to the participants' definition of leadership. The definitions were gathered from a pre-program application that served as a baseline of the initial concept of "leadership" before participation in this program. A content analysis was conducted from these archival data. "Content analysis is a technique that enables researchers to study human behavior in an indirect way, through an analysis of their 
communications" (Fraenkel \& Wallen, 1999, p. 405). Participants answered the application questions before the program and again at the culmination of the program.

Participants. Participants were women from the Women's Learning Circle (WLC), an annual event hosted by the Collegiate Panhellenic Council (CPC). Adams and Keim (2000) found that sorority chapter presidents took a more participatory/collaborative approach and practice of developing a trusting and supporting environment while encouraging others to develop leadership skills than did their male counterparts. For many women, sorority membership has become a successful method of social integration and creation of support systems. For instance, sorority membership has been noted as a method to meet other women who share common goals and values.

CPC hosts recruitment activities prior to the first week of classes and traditionally accepts only first-semester freshmen women who have been involved in high school organizations and held leadership positions prior to enrolling in the university. The sample for this study consisted of 54 first semester women, approximately $8 \%$ of the freshmen women involved in CPC sororities. The WLC members were reflective of the general population of the target university, with sorority members comprising approximately $7 \%$ of the undergraduate female student population. The CPC population is $99 \%$ White and the members of the WLC group were reflective of this demographic. Female students were selected and encouraged to apply to the program by chapter presidents and organization advisors. The women were selected based on their application and interest in future leadership positions.

The Program. WLC was developed as a leadership training program for freshmen CPC sorority women to meet regularly to discuss issues pertinent to college life, leadership, and involvement. The WLC program utilizes critical reflection and experiential learning through the medium of conversation and media. Each learning circle contained six women from various chapters. The groups were formed based on the applicants' stated interest and hobbies. The students received various modules as discussion topics, such as leadership, body image, and selfesteem. The small group learning circles viewed an assigned film associated with the module topic and utilized a literature circle method to explore the information (Stein \& Beed, 2004). The literature circle assigned individual roles (i.e., connector, illustrator, passage master, questioner, and summarizer) based on the task required to influence learning and synthesize the information. The program used entertainment media to inform leadership teaching and practice in higher education. Some researchers have stated that the use of entertainment to teach leadership concepts can be especially powerful (McMahon \& Bramhall, 2004). Entertainment media has the ability to make complex concepts visible, a necessary but rare ingredient in successful leadership development efforts.

The pedagogical framework for using selected movies, television, literature, and music to teach leadership is based on Kolb's experiential learning cycle theory (Kolb, 1984). Kolb's cycle provides an effective way to frame learning experiences and is suitable for planning the use of media to develop leadership. The model presumes that participants engage in an experience, process that experience, generalize learning from the experience, and then apply those learnings to new situations. Kolb's model works equally well for training students in a specific skill or 
educating them on a particular topic. The difference in these cases is that the experience is framed or set up in a specific way before the participant engages in the activity. After viewing a movie in small groups, the students are instructed by the group leader to identify particular characteristics concerning leadership. The experience is then debriefed specifically within the frame that was provided beforehand. In this process, a particular outcome or skill is desired, whereas in the developmental process participants are asked to develop their own insights from the experience. While watching a movie or reading a piece of literature may appear to be a passive activity, it is, for the purpose of the program, an experiential activity.

Data Analysis. The qualitative data were analyzed by using a deductive approach with a set of archival data responses. Data were de-identified, coded, and sorted according to the learning circle groups. A confidential code number, using a letter to denote the small group (A$\mathrm{H}$ ) and a number corresponding to the total number of participants in each group, was provided on each respondent card. First-level coding was based on carefully examining the data and selecting phrases, words, or stories that, taken individually, contained a single meaning. For the purpose of this study, first-level coding involved reading half of the applications and making line-by-line notations in the margins. The notations indicated key words or phrases. The coding was done manually, with hand-written notes made on the application. During the coding process, memos were written to detail emerging themes or concepts that required further exploration. The codes were then distilled, abbreviated, and written on individual note cards. The data cards listed the comments along with the participant identification codes.

Second-level coding consisted of examining and collapsing codes into categories or higher-level concepts. As data collection and analysis continued, comparison indicated commonalities and differences among categories. After review, data cards were created and sorted based on the common themes that emerged from the data. The researchers developed a master list of common themes and categories, and then compiled the themes accordingly.

According to Lincoln and Guba (1985), in the third and final stage of coding relationships between categories are formed and ideas are developed that lead to hypotheses. Further coding of the remaining applications tested the hypotheses. Theoretical triangulation was considered as final categories and representative quotes were selected to give voice to the participants.

\section{Results}

The participants were asked, "How do you define leadership?" The themes did not indicate students' defined leadership as a process or as one having influence, but rather identified leadership as possessing specific characteristics and traits. The themes were not influenced by small learning circles, past high school involvement, chapter affiliation, or interest groups. In particular, respondents stated the concept of leadership as one possessing a certain set of characteristics that were maintained by individual beliefs, morals, and value systems. The respondents often described leadership and leaders interchangeably, which may indicate their inability to differentiate between the concept of leadership and what makes one an effective leader. Therefore, two overarching themes emerged: leader traits and leadership behaviors. 
Within the theme of leader traits, the major themes were (a) belief in self/cause, (b) integrity (ability to do the right thing), (c) selflessness, (d) passion, (e) mutual respect, (f) ability to unite a group and work with others, (g) ability to compromise, (h) dependability, and (i) confidence. Other themes associated with leader were (a) being genuine, (b) inspiring others, and (c) showing mutual respect. (Italics is the following quotes from respondents were added for emphasis by the researchers.) One respondent emphasized several of these traits:

I define leadership as the occurrence of your own belief in yourself and your ability to do the right thing, being so genuine that it inspires others to look at you and look to you for help in their own struggle for self-worth and achievement. The greatest leaders are not the ones who went looking for power but the ones whom it was given to because of their selfless personal achievement as an individual. (A4)

Other respondents mentioned this notion of selfless leadership but added subthemes of passion and working hard for others for a greater cause:

To be a good leader a person must be willing to selflessly serve a cause that they have an extreme passion for. (G3)

A leader does not work hard to be glorified, but works hard for others and for something greater than themselves. (A5)

The second theme was leader behaviors. Some respondents focused on the ability to unite a group and to be someone whom others could trust and depend on as an important leadership behavior. This included constructs of being able to work with others, listen, and compromise to accomplish a goal as a team:

Being able to lead means you must be able to unite a group, create compromise, and be dependable. A leader should never be controlling. As a leader, one should always be able to work and listen to others. (B4)

Respondents spoke to the issue of leaders being role models or those who set an example for others to follow.

I believe leadership is being an active role model for another person. It is present in every facet of our lives and one must not be proclaimed a "leader" in order to show leadership abilities. (H2)

Many respondents stated that mutual respect was an important leadership behavior. Leadership in my mind is defined as mutual respect. You can lead people all you want, but how the people you are leading actually respond to you is the true test. You need to be respected as a leader; you need to respect the people you are leading. (D2)

Some respondents stated that leaders should be competent (knowledgeable), proactive, and inspiring.

Leaders exhibit positive qualities so that people choose to behave like them, but are also able to take on the responsibility to being a role model. Leadership is about inspiring others for a mutual goal and direct everyone until the goal is accomplished. (H5) Sometimes a leader has to exude courage and confidence and do "the right thing" even when it is not popular. Women leaders recognized the importance of speaking up - having a voice:

[A leader is] somebody who is not afraid to step up and say something, even if others may disagree, a leader does not care what others will think of them. (E5)

The respondents also associated leaders with being able to take responsibility, take charge, administer authority, be visionary, and be goal oriented with their followership. Below is 
a sampling of responses that lend voice to the behaviors necessary for leaders, as well as the distinctions made between terms.

I think that leadership involves having a clear destination in mind, knowing where you are and where you want to be and taking the steps to achieve that goal. (D6)

I believe leadership is the ability to take charge of a situation and administer the correct level of authority and responsibility that comes with the role of being a leader. (F4)

The respondents identified several leadership traits and active leader behaviors that were essential to be a good leader. For example, leaders are to be genuine, inspiring, and selfless servants who promote followership through role modeling. Leaders are to be mutually respectful, with the ability to be uniting, creating compromise in others. Leaders are dependable, work well with others, and listen while stepping up and having something to say. Leaders are not power seekers but rather take responsibility and are knowledgeable, proactive, goal oriented, and productive.

\section{Discussion}

The results indicate that these respondents defined leadership interchangeably by leadership traits and leader behaviors. They appeared to be clear on how they viewed effective leaders.

Results of the study confirm findings similar to those reported by Burns (1978), who captured five behavioral traits: intelligence, self-confidence, determination, integrity, and sociability. Each of these dimensions was clearly identified in this study, creating the distinctive viability of continued study concerning leadership with this population. While Hoyt (2007) found that gender was essential to the contemporary notions of effective leadership styles in its various forms, the current study found definitions of leadership closely assigned with leadership theory. Hoyt (2007) concluded that it was unclear how important traits were to leadership; however, the current study found leaders' traits to be an essential part of the respondents' ideals of an effective leader.

The responses from the women in this study concerning leadership and leader roles were aligned with the description of transformational leadership. That is, respondents described the traits and behaviors postulated by leadership theorists who study transformational leadership. For instance, leaders were to be the farsighted risk takers, role models, and change agents, much like those whom Lussier and Achua (2007) described. Respondents indicated that a leader's beliefs, morals, and values should align with those of their followership, particularly when making decisions for the group. Respondents would have would-be leaders put their beliefs into action. Self-esteem, achievement, and willingness to work (but not for glory or power) was critical, as well as embracing a higher purpose than oneself. In addition, leaders were asked to provide voice for those who might be afraid to speak up for themselves, without regard for self. The current study confirms research by Adams and Keim (2000), who found that sorority chapter presidents took on a participatory/collaborative approach and practice of developing a trusting and supporting environment while encouraging others to develop leadership skills. In fact, the sorority chapters who participate in the WLC program at the target university may serve as a model for other sororities and/or programs that wish to create transformational leaders. 
According to Tinto (1993), as students become involved in an organization such as a sorority, it is a natural progression for those students to become leaders. The current study featured freshman sorority women with previous leadership experience who, as first-year college students, had sought membership in a student organization (sorority). As seen in their responses, it is reasonable to assume that these women had high expectations for leaders and were likely striving to acquire and/or maintain the type of leadership skills that they expected from others. The leadership skills that they appeared to seek require a certain amount of assertiveness, selfawareness, self-confidence, commitment, stability, integrity, intelligence, flexibility, and sensitivity to the needs of others, similar to the traits that Lussier and Achua (2007) identified and similar to those that Burns (1978) specified. Such expectations may have far-reaching implications for programming for women on a collegiate level.

\section{Implications}

Elias et al. (2006) noted that transformational leaders use structures and relationships to achieve and maintain change. Likely, the respondents sought the particular structure and relationships that a sorority offers as a way to become socially integrated into the academic and social environment, as suggested by Tinto (1993). The implication is that females who are entering college with leadership experience will intentionally seek structures and relationships that foster leadership development. Thus, institutions of higher learning and/or programs interested in creating change for women may consider what types of structures, programs, and student organizations foster the building of relationships and the development of leadership skills. As Tinto (1993) pointed out, a majority of early terminations from college are tied to the student's quality of experiences after entering college; having programs designed specifically for this population may lead to program and university sustainability and integration.

In order to understand fully the implications of this study, it will be important to infuse results from a quantitative study and repeat the qualitative study with women once they have completed the leadership program. For the quantitative study, it would be beneficial to use the Student Leadership Practice Inventory (SLPI) developed by Kouzes and Posner (Kouzes \& Posner, 2008; Posner, 2004) to identify specific behaviors and actions that the WLC students report using when they are at their personal best as leaders after they complete the WLC program. These behaviors could then be categorized into five leadership practices congruent to the five exemplary practices related to transformational leaders. The scores from the SLPI at other institutions are stored in a database and can be used as a comparative measure. The SLPI database divides student leaders into several categories; fraternity and sorority and residence hall directors. The results should be then compared to those of fraternity and sorority leaders from other institutions. The review of the results from the completed SLPI could offer invaluable insight regarding how students view their individual leadership skills. It would be interesting to see whether the students make a connection between leadership skills and the definition of leadership. It would also be interesting to determine whether they are able to identify themselves as transformational leaders after completion of the leadership training program.

Further research should be conducted with sorority chapter presidents who have had members participate in WLC programs to evaluate the students' performance over time. The 
influence of transformational leaderships and the relationship to female college students' perceptions of leadership should be explored due to the many characteristics, traits, and behaviors that are consistent with transformational leadership descriptions. Based on the findings of this study, there is a need to determine how the traits and behaviors are transferred from leader to participant.

Additional research is needed to explain the interplay of the dynamics at work. The current study focused solely on first-semester freshmen; continued enrollment and organizational involvement might influence further perceptions of leadership over time. Longitudinal research that follows students throughout their collegiate tenure and focuses on how perceptions of leadership change over time could shed light on leadership dynamics.

It is unclear how comments by the study participants may affect the future leadership selection for sorority chapters, given that participants articulate their expectations of their leaders and how those leaders may or may not display specific characteristics, traits, and behaviors.

Additional research in this area would be enlightening. Posner and Rosenberger (1998) reported that students did not vary in their leadership practices when involved in a one-time leadership project versus a project or program lasting for an entire academic year. However, students who return for a second year in a leadership position have been shown to engage significantly in leadership behaviors more often than those who were just starting in the same position (Posner \& Rosenberger, 1998). Cress et al. (2001) similarly found that students who had participated in a formalized leadership program demonstrated significant growth in leadership skills.

\section{References}

Adams, T., \& Keim, M. (2000). Leadership practices and effectiveness among student leaders. College Student Journal, 34, 259-271.

Appleton, J. V., \& King, L. (1997). Constructivism: A naturalistic methodology for nursing inquiry. Advances in Nursing Science, 20(3), 13-22.

Astin, A. W. (1993). What matters in college: Four critical years revisited. San Francisco, CA: Jossey-Bass.

Astin, A. W. (1996). Involvement in learning revisited: Lessons we have learned. Journal of College Student Development, 37, 123-134.

Bass, B. (1990). Handbook of leadership: Theory, research, and managerial applications (3rd ed.). New York, NY: Free Press.

Burns, J. M. (1978). Leadership. New York, NY: Harper \& Row. 
Chickering, A. W., \& Reisser, L. (1993). Education and identity (2nd ed.). San Francisco, CA: Jossey-Bass.

Cress, C. M., Astin, H. S., Zimmerman-Oster, K., \& Burkhardt, J. C. (2001). Developmental outcomes of college students' involvement in leadership activities. Journal of College Student Development, 42, 15-27.

Dugan, J. P. (2006). Explorations using the social change model: Leadership development among college men and women. Journal of College Student Development, 47, 217-225.

Eagly, A. H., \& Carli, L. L. (2003). The female leadership advantage: An evaluation of the evidence. Leadership Quarterly, 14, 807-834.

Eagly, A. H., Johannesen-Schmidt, M. C., \& van Engen, M. L. (2003). Transformational, transactional, and laissez-faire leadership styles: A meta-analysis comparing women and men. Psychological Bulletin, 129, 569-591.

Elias, M., O’Brien, M., \& Weissberg, R. (2006). Transformative leadership for social emotional learning. Principal Leadership (Middle School Ed), 7(4), 10-13.

Endress, W. (2000). An exploratory study of college students' self-efficacy for relational leadership: The influence of leadership education, cocurricular involvement, and oncampus employment (Unpublished doctoral dissertation). University of Maryland, Baltimore.

Fraenkel, J. R., \& Wallen, N.E. (1999). How to design and evaluate research in education. New York, NY: McGraw-Hill.

Garza, O. G. (2000). A ten-year follow-up study of the completer's perceptions of the Texas A\&M community college and technical institute leadership development programs: Minority leadership project. Dissertation Abstracts International. (UMI No. AAT9980148)

Gellin, A. (2003). The effect of undergraduate student involvement on critical thinking: A metaanalysis of the literature 1991-2000. Journal of College Student Development, 44, 746762.

Guba, E. G. (1990). The alternative paradigm dialog. In E. G. Guba (Ed.), The paradigm dialog (pp. 17-27). Newbury Park, CA: Sage.

Hoyt, C. (2007). Women and leadership. In P. Northouse (Ed.), Leadership: Theory and practice (4th ed., pp. 265-293). Thousand Oaks, CA: Sage.

Hughes, D., \& DuMont, K. (1993). Using focus groups to facilitate culturally anchored research. American Journal of Community Psychology, 21, 775-806. 
Kezar, A., \& Moriarty, D. (2000). Expanding our understanding of student leadership development: A study exploring gender and ethnic identity. Journal of College Student Development, 41, 55-68.

Kolb, D. (1984). Experiential learning: Experience as the source of learning and development. Englewood Cliffs, NJ: Prentice Hall.

Komives, S., Lucas, N., \& McMahon, T. (1998). Exploring leadership: For college students who want to make a difference. San Francisco, CA: Jossey-Bass.

Kouzes, J., \& Posner, J. (2008). The student leadership challenge: Five practices for exemplary leaders. San Francisco, CA: Jossey-Bass.

Kuh, G. D., \& Lund, J. P. (1994). What students gain from participating in student government? New Directions for Student Services, 66, 5-17.

Lamborghini, N. M., \& Dittmer, R. (2002). Northern Essex Community College: Student leadership development program. In National Association of Student Personnel Administrators (Eds.), Bridges to student success (pp. 10-12). Washington, DC: Magnificent.

Lincoln, Y. S., \& Guba, E. G. (1985). Naturalistic inquiry. Beverly Hills, CA: Sage.

Logue, C. T., Huchens, T. A., \& Hector, M. A. (2005). Student leadership: A phenomenological exploration of postsecondary experience. Journal of College Student Development, 46, 393-408.

Lussier, R., \& Achua, C. (2007). Leadership: Theory, application, and skill development (3rd ed.). Mason, $\mathrm{OH}$ : Thomson.

McMahon, T. R., \& Bramhall, R. (2004). Using entertainment media to inform student affairs teaching and practice related to leadership. New Directions for Student Services, 108, 6170 .

Nahavandi, A. (2006). The art and science of leadership (4th ed.). Upper Saddle River, NJ: Pearson Prentice Hall.

Pascarella, E. T., \& Terenzini, P. T. (2005). How college affects students: A third decade of research (Vol. 2). San Francisco, CA: Jossey-Bass.

Polleys, M. S. (2002). One university's response to the antileadership vaccine: Developing servant leaders. Journal of Leadership Studies, 8(3), 117-130.

Posner, B. Z. (2004). A leadership development instrument for students: Updated. Journal of College Student Development, 45, 443-456. 
Posner, B. Z., \& Brodsky, B. (1994). Leadership practices of effective student leaders: Gender makes no difference. NASPA Journal, 31(2), 113-120.

Posner, B. Z., \& Rosenberger, J. (1998). The impact of situational factors on students leadership behaviors. Unpublished manuscript, Santa Clara University.

Pugh, D. (2000). College student leadership development: Program impact on student participation (Unpublished doctoral dissertation). University of Georgia, Athens.

Romano, C. R. (1996). A qualitative study of women student leaders. Journal of College Student Development, 37, 676-683.

Smedley, B. D., Myers, H. F., \& Harrell, S. P. (1993). Minority-status stresses and the college adjustment of ethnic minority freshmen. Journal of Higher Education, 64, 434-452.

Stein, D., \& Beed, P. (2004). Bridging the gap between fiction and nonfiction in the literature circle setting. The Reading Teacher, 57, 510-518.

Thompson, P. (2000). Radical constructivism: Reflections and directions. In L.P. Steffe, \& P.W. Thompson (Eds.). Radical constructivism in action: Building on the pioneering work of Ernst von Glaserfelt (pp. 412-448). London: Falmer Press.

Thorp, L., Cummins, R., \& Townsend, C. (1998). Women's self-perceived leadership skills in a collegiate agricultural education course. Journal of Agricultural Education, 39(1), 55-62.

Tinto, V. (1993). Leaving college: Rethinking the causes and cures of student attrition. Chicago, IL: The University of Chicago Press. 


\section{Author Biographies}

Tammie Preston-Cunningham currently serves as an Assistant Lecturer in the Department of Agricultural Leadership, Education and Communications at Texas A\&M University. She has worked in Fraternity \& Sorority Life for over fifteen years and higher education for over twenty years.

Chanda D. Elbert currently serves as an Associate Professor in the Department of Agricultural Leadership, Education and Communications at Texas A\&M University. She has developed and taught university courses in women's leadership, leadership theory, multicultural leadership, program evaluation and organizational accountability.

Kim E. Dooley is the Associate Dean for Academic Operations for the College of Agriculture and Life Science and Professor in the Department of Agricultural Leadership, Education and Communications. She oversees all undergraduate academic affairs, distance and continuing education programs, and international academic programs for the College. 